\title{
DISCURSO DE ÓDIO EM MÍDIAS SOCIAIS COMO ESTRATÉGIA DE PERSUASÃO POPULAR
}

\section{HATE DISCOURSE IN SOCIAL MEDIA AS PERSUASIVE STRATEGY FOR POPULISM}

\author{
Karen Tank Mercuri* \\ Rodrigo Esteves de Lima-Lopes ${ }^{\star}$
}

\section{RESUMO}

Este artigo busca compreender o momento atual, dando um passo atrás, para mostrar que em uma situação anterior à campanha eleitoral de 2018, já havia indícios do populismo digital (CESARINO, 2018): o aparato digital e a mobilização (produção e compartilhamentos de bashtags no Twitter), bem como a tática política de estabelecer um eixo sintagmático amigo-inimigo. Mais especificamente, o intuito aqui é analisar discussões políticas, dentro do quadro linchamento virtual (MACEDO, 2018), de duas maneiras: (i) por suas conexões, utilizando modelos de redes aplicados às redes sociais online, conforme descritos nos trabalhos de Recuero $(2005,2014)$ e Lima-Lopes $(2017,2018)$ e; (ii) pelo discurso contido nas postagens, segundo o Sistema de Avaliatividade (MARTIN e WHITE, 2005) e suas aplicações em Língua Portuguesa (VIAN JR et. al, 2010). Foi considerada para esta pesquisa a utilização no Twitter da basbtag \#Dia28EuVouTrabalhar, criada e disseminada com o intuito de contrariar a Greve Geral marcada para o dia 28 de abril de 2017, cujo objetivo era protestar contra as reformas trabalhista e da previdência. A raspagem de dados e os grafos de conexão foram feitos com o auxílio dos softwares NodeXL e Gephi, respectivamente. Ao final, observou-se que os principais influenciadores na rede tinham grande importância na disseminação do discurso de ódio, pois o grande número de seguidores possibilitou o espalhamento em larga escala. Vale ressaltar que o nó central da rede estudada era um deputado estadual do Rio de Janeiro e filho de um político com pretensão à presidência da República. A principal avaliação expressa nas postagens, em relação aos sentimentos, foi a insatisfação com o partido político que se manteve na presidência do Brasil por catorze anos e que fora interrompido por um impeachment, no ano anterior a esta greve. Já em relação ao Julgamento, as postagens revelaram uma descrença quanto à ética e confiabilidade tanto em relação aos grevistas quanto aos organizadores. Com isso, pode-se observar que a repetição e padronização de discursos estigmatizados, bem como sua pulverização em mídia social, foram - e ainda são - utilizadas como instrumento para conseguir o apoio popular.

Palavras-chave: discurso de ódio; mídias sociais; análise de redes; avaliatividade; populismo.

\footnotetext{
* Doutoranda na Universidade Estadual de Campinas, Unicamp, Campinas, SP, Brasil. k001935@dac. unicamp.br

Orcid: https://orcid.org/0000-0002-7623-5290

** Universidade Estadual de Campinas, Unicamp, Campinas, SP, Brasil. rll307@unicamp.br

Pesquisa financiada pelo CNPq (processo 422111/2018-0).

Orcid: https://orcid.org/0000-0003-3681-1553
} 


\section{ABSTRACT}

This article takes a step backwards and tries to understand our current moment by analyzing social media context in a 2017 social hashtag movement. Our data show that prior to the 2018 presidential campaign, there was already evidence of digital populism (CESARINO, 2018). The digital apparatus for mobilization (production and sharing of Twitter hashtags), as well as the political strategy of establishing a friend-enemy syntagmatic axis. More specifically, the aim here is to analyze political discussions, within the framework of virtual lynching (MACEDO, 2018), in two ways: (i) by means of network models applied to online social networks, as described in Recuero's works $(2005,2014)$ and Lima-Lopes' works $(2017,2018)$ and; (ii) by an analysis of the appraisal discourse (MARTIN and WHITE, 2005) present in some Twitter posts and its applications to Portuguese (VIAN JR et. al, 2010). Our analysis relies on the Twitter hashtag \#Dia28EuVouTrabalhar. It was created and disseminated aiming at countering the General Strike scheduled for April 28, 2017, in order to protest against labor and social security reforms. Data scraping and connection graphs were performed with the aid of NodeXL and Gephi software, respectively. As a result, we could observe that the main influencers in the network were of great importance in the dissemination of hate discourse, because the large number of followers allowed such discourse to spread on a large scale. It is worth mentioning that the central node of the studied network was a state deputy from Rio de Janeiro and the son of a politician, who later got elected as the presidency of the Republic. Feelings regarding dissatisfaction were the more common. They were projected towards the political party that was in office in Brazil for fourteen years. Such a party had its last term interrupted by an impeachment in the year previous to this strike. Regarding the Judgment, the posts revealed a disbelief concerning ethics and reliability both in relation to the strikers and the movement organizers. We could observe that the repetition dispersion and standardization of stigmatized discourses were very common tools in the 2017 context. It is also relevant to keep in mind that such strategies still are an important instrument to obtain popular support in social media. Keywords: hate discourse; social networks; network analysis; evaluation; populism.

\section{INTRODUÇÃO}

As redes sociais online têm sido um meio de comunicação importante na atualidade. $\mathrm{O}$ fato de as pessoas estarem conectadas em redes eletrônicas propicia um maior poder de organização política e de intervenção (CASTELLS et. al, 2006). De fato, a Internet, sobretudo as mídias sociais (Facebook, Twitter, Youtube, entre outras), contribuiu para "ampliar as denúncias de situações de violência, promover o embate político e quebrar certos tabus" (MERCURI, 2016, p. 60).

No entanto, essa conexão de muitos para muitos pode ser conflituosa e, inclusive, causar danos pessoais e até à democracia. Segundo a pesquisa de Hoffman (1996), a Internet tem se tornando uma importante ferramenta para divulgação e consolidação de ideias conservadoras por grupos extremistas nos Estados Unidos, motivando a participação e recrutando novos apoiadores, muitas vezes letrados digitalmente, mas que se deixam guiar por uma cartilha ideológica. Já Lima-Lopes 
(2018) verificou em seu estudo algo semelhante e que estava ocorrendo no Brasil: mobilização conservadora e intolerância à diversidade de pensamento.

Diante da realidade dessas tensões em meio digital, focaremos nossa atenção ao discurso de ódio motivado por discussão política. Embora ocorra na Internet, não podemos deixar de mencionar que ele é apenas uma parte do linchamento virtual (MACEDO, 2018). Este, de acordo com Macedo (2018), é um fenômeno que permeia a fronteira do online e offline, bem como da liberdade de expressão e do crime contra a dignidade humana, entre outras. Ainda segundo essa autora, há vários gatilhos para que um linchamento virtual aconteça, mas aqui falaremos da intolerância política e como ela impacta a sociedade. No Brasil, há uma polarização política entre representantes da esquerda e da direita, que vem sendo significativamente rearranjada, no contexto antagonístico (CESARINO, 2020), e isso tem fomentado discursos de ódio dentro e fora das mídias sociais, como já vem sendo observado desde a eleição presidencial de $2014^{1}$.

O encontro com o "outro" que me despossui, que me obriga a modificar a minha maneira de pensar sobre mim mesmo, de me reinventar nessa relação, que me empurra para fora de meus interesses, que abre meus horizontes e perspectivas, que me enriquece com outras possibilidades de vida e pensamento - esse "outro" deve ser destruído e eliminado (SAFATLE, $2016^{2}$ apud MERCURI, 2016, p. 40)

Segundo Cesarino $(2018,2020)$, esse "outro" visto como inimigo funciona também como um perigo virtual iminente para a nação ou grupo. $\mathrm{O}$ mecanismo populista explora o antagonismo amigo-inimigo atacando adversários ou criando alertas de ameaça, invertendo enunciados para, assim, fortalecer seu líder e seu grupo. Ao provocar indignação, cria em seus seguidores uma "sintonia afetiva" (MALY, 2020, p. 453) que resulta em uma reação direta e grande propagação de bashtag, um "significante vazio que articula "multidões" insatisfeitas online" (CESARINO, 2020, p. 99). Embora esses estudos sejam referentes aos períodos da campanha eleitoral no Brasil e do governo Bolsonaro, também foi possível notar semelhanças de estratégias em um período anterior, como será mostrado neste artigo.

Mais especificamente, a situação observada neste trabalho é convocação para uma greve geral em 28 de abril de 2017, contra as reformas trabalhista e da previdência. Embora o interesse da greve fosse impedir a aprovação dessas reformas e, assim, assegurar que os direitos dos trabalhadores fossem mantidos, ela recebeu

1. Como neste caso de Linchamento Virtual, descrito por (MERCURI, 2016), disponível em: $<$ https://linchamentosvirtuais.wordpress.com/2016/07/09/linchamento-virtual-de-um-grupo-deindividuos >. Acesso em: 09 jul, 2016.

2. Cf. Safatle (2016). 
um movimento contrário, intenso, motivado no Twitter pela utilização da basbtag: \#Dia28EuVouTrabalhar. Como foi a basbtag mais utilizada naquele dia, achamos oportuno verificar os discursos que a acompanhavam.

Este estudo se pauta no Sistema da Avaliatividade (MARTIN e WHITE, 2005), para analisar e classificar as avaliações, sobre algo ou alguém acerca da greve geral, instanciadas em comentários do Twitter. Com isso, verificaremos quem são os linchados virtualmente e de que maneira isso se dá. Além disso, é importante verificar se há um padrão na linguagem e o que ela pode indicar em termos de comportamento político-social.

No entanto, de acordo com Thompson e Alba-Juez (2014) como a avaliação tem múltiplas faces, é interessante se trabalhar com mais de um parâmetro ou teoria para compreensão do fenômeno. Na mesma direção, Blommaert (2020) afirma que a análise do discurso na era pós-digital também deve levar em conta as infraestruturas digitais e os sistemas de comunicação, atentando-se à maneira com que eles moldam a produção, circulação, aceitação de discursos, incluindo o discurso político, e a relação entre atores. Por isso, conforme proposto por LimaLopes (2018), utilizaremos também como metodologia complementar a Ciência das Redes.

Segundo Barabási (2003), todas as relações dentro dos mais diversos campos do saber podem, de alguma forma, constituir-se em rede em que indivíduos são representados por nós e as relações entre eles são expressas por meio de linhas de ligação. Não cabe aqui a análise dessas ligações por motivos interpessoal ou emocional, mas pela possibilidade de militância político-social oferecida pela própria estrutura das mídias sociais (CASTELLS, 2014).

Sendo assim, a junção da Avaliatividade com a Ciência das Redes é uma forma de construir um aporte teórico-analítico que permita uma compreensão mais consistente de como a basbtag pesquisada circula, como é construída a avaliação sobre a greve e como esse mecanismo se assemelha ao populismo digital.

\section{AVALIAÇÕES DOS SENTIMENTOS E AÇÕES HUMANAS}

Os escritores/falantes marcam sua posição no texto ao se expressarem. Essas marcas podem "indicar como eles aprovam ou desaprovam, entusiasmam-se ou odeiam, aplaudem ou criticam os seres e os fatos do contexto social e como esses agentes constroem a identidade de seus leitores/ouvintes" (CABRAL, 2007, p. 53). Para Martin e White (2005) é possível encontrar no texto elementos que demostrem essas avaliações, frutos de sentimentos e valores de uma comunidade. 
Assim, configuraram o Sistema de Avaliatividade que, embora pensado para a Língua Inglesa, é possível a partir da perspectiva sistêmico-funcional da linguagem ${ }^{3}$ (Cf. Halliday e Matthiessen, 2014), analisar como tais mecanismos ocorrem em Língua Portuguesa (VIAN JR. et al, 2010).

O Sistema de Avaliatividade divide-se em três grandes subsistemas (MARTIN e WHITE, 2005): (i) Atitude: posição que se assume perante algo ao avaliar o mundo e expressá-lo na linguagem; (ii) Engajamento: postura do produtor do texto em relação aos seus interlocutores (em alinhamento ou desalinhamento com os participantes) e (iii) Gradação: utilização dos recursos léxico-gramaticais para enriquecer as análises de atitude e engajamento, amplificando ou mitigando os significados.

Neste artigo, devido à natureza das postagens selecionadas, focaremos no subsistema Atitude, mais especificamente em seus subníveis: Afeto e Julgamento. O primeiro por refletir, no discurso linguístico, o comportamento emocional dos escritores, positiva ou negativamente, em relação a algo ou a alguém; e o segundo por estar relacionado às avaliações éticas do comportamento humano, que são baseadas na legalidade ou em convenções sociais.

O afeto é um recurso para avaliar o registro de sentimentos (positivos ou negativos), expressos explícita ou implicitamente, atribuindo qualidades aos participantes ou aos processos (ALMEIDA, 2010). Martin e White (2005) propõem três conjuntos, nos quais essas emoções estariam agrupadas: (i) Felicidade/ Infelicidade: sentimentos ligados a emoções pessoais, que podem deixar uma pessoa feliz ou infeliz; (ii) Segurança/ Insegurança: emoções relacionadas ao bem-estar social. É o sentir-se (in) seguro em relação às coisas do mundo ou a certas pessoas; (iii) Satisfação/ Insatisfação: sentimentos relacionados ao alcance ou frustação de um objetivo a ser alcançado/ realizado, por participantes ou expectadores da ação.

Já os julgamentos dependem da cultura ou das experiências, expectativas e crenças particulares em determinada situação. $\mathrm{O}$ julgamento pode ser subdividido em dois tipos: de Estima e de Sanção Social. O Julgamento de Estima envolve admiração ou crítica sem implicações legais. Suas unidades de análise são: Normalidade (frequência do fato), Capacidade (quão capaz é) e Tenacidade (quão resoluto é). Já o Julgamento de Sanção Social implica elogio ou condenação, mas baseado na legalidade. Suas unidades de análise são: Veracidade (é verdade, é confiável?) e Propriedade (é ético?).

3. (Cf. Halliday e Matthiessen, 2014). 
Assim, pautaremos as análises linguísticas dos textos escritos que acompanham a hashtag pesquisada, verificando como se constrói a avaliação sobre pessoas, grupos ou atos diante à convocação de greve geral.

\section{CONEXÕES ENTRE DISCURSOS EM MÍDIAS SOCIAIS}

Com base nos trabalhos de Recuero $(2005,2014)$ e Lima-Lopes (2017, 2018) traremos o conceito de redes complexas em mídias sociais para analisar a interatividade no Twitter, no dia 27 de abril de 2017, em torno da basbtag \#Dia28EuVouTrabalhar. De acordo com Lima-Lopes (2018) a ciência das redes pode ser um importante complemento nos estudos da linguagem, visto que visa observar a natureza das interações e, assim, propicia um melhor entendimento do contexto para a análise discursiva.

Uma definição possível para a Ciência das Redes, ou Network Science, seria: um domínio interdisciplinar de pesquisa que visa a compreender como redes complexas em diferentes áreas do conhecimento, incluindo ciências biológicas, ciências sociais, política, infectologia entre diversas outras, em contextos online e offline (BARABÁSI, 2003). Uma de suas características principais é a percepção das redes como fenômeno de maneira a estabelecer modelos matemáticos e preditivos (National Academy of Sciences, 2005, p. 20). No que tange a este trabalho a análise de redes pode ajudar a compreender os diversos atores sociais, trazendo à tona a natureza de sua relação no espaço interativo representado pelas mídias sociais.

Como coloca Lima-Lopes (2017), ao discutirmos os processos de interação por esta perspectiva, dentro do âmbito da Comunicação Mediada por Computador, devemos levar em conta que os indivíduos se conectam tanto por de forma aleatórias como por relações sociais. A primeira se caracteriza por relações que podem ocorrer de forma ocasional, ao passo que a segunda estaria motivada pelas diferentes relações do ambiente social (BARABÁSI; ALBERT, 1999; SCOTT, 2013; BARABÁSI, 2003). Assim, como coloca Watts (2003), as redes podem ser indicativas de nossa identidade social, representando nossas características. Cada indivíduo interpretaria papéis diversos em cada uma das redes que participa, uma rede cresceria e se desenvolveria por meio da inserção de novos participantes que estabeleceriam novas ligações e levariam a uma nova topologia de relações (Barabási e Albert, 1999). 
Para Scott (2013) e Barabási (2003) as bases para a representação das análises de rede foram desenvolvidas pelo matemático Ëuler, ${ }^{4}$ criador dos teoremas dos grafos, uma forma de representação na qual nódulos se conectam por linhas e formam uma rede (RECUERO, 2005). Tal representação implica em novas unidades de análise que, de acordo com Lima-Lopes (2017) ao discutir o trabalho de Scott (2013), poderiam ser definidas como:

- Nó: representa um indivíduo dentro de uma rede.

- Arestas: são as ligações entre tais indivíduos.

- Força de conexão: expressada como variação em espessura das arestas de uma rede, expressa a força de uma conexão.

- Rede (não)dirigida/direcionada: indica a direção entre as interações, redes dirigidas trazem essas informações, redes não dirigidas a ignoram.

- Graus: são medidas estatísticas que avaliam a conectividade de um nó, entre elas estariam centralidade (mensurando a entrada e a saída de conexões).

- Clusters (sub-redes): É um coeficiente de agrupamento, mede a proporção de nós interconectados.

- Hub: É um componente da rede cujo número de conexões está acima da média, possibilitando a relação entre indivíduos que, sem ele, talvez não estivessem conectados.

Recuero (2014) discute o uso de algumas métricas para criação de grafos de interações oriundas do Twitter. São elas:

- Centralidade Betwenness (FREEMAN, 1979 apud RECUERO, 2014): está associada ao número de caminhos que passam por esse nó até chegar em outros grupos. Quanto maior essa métrica, mais "ponte" ele é. Isso implica na sua influência no espalhamento de informações.

- Centralidade Eingenvector (BONACICH, $1972^{5}$ apud RECUERO, 2014): leva em consideração não só as conexões de um determinado nó, mas também dos nós em sua vizinhança. A importância e prestígio de um ator (nó) é medida verificando se atores que o citam, também são muito citados por outros.

4. O artigo do matemático e físico suíço Leonhard Euler, publicado em 1736, sobre o problema das sete pontes de Königsberg, é considerado o primeiro resultado da teoria dos grafos.

5. BONACICH, P. (1972) Factoring and weighting approaches to status scores and clique identification. Journal of Mathematical Sociology. v. 2, pp. 113-120. 
- Modularidade: é uma métrica de rede. Aplica-se a modularidade para separar os grupos (clusters), identificar outros nós centrais para cada um dos grupos e, com isso, verificar a relevância deles tanto nas sub-redes como na rede como um todo.

Essa concepção de redes passou a ser aplicada à Sociologia, na década de 60 e 70, para estudos e análises das estruturas sociais. Para essa adaptação, foi preciso definir outras unidades de análise, tais como: direção e força de conexão, quantidade de relações (conexões) entre dois pares de atores, grau de complexidade (número de conexões), densidade da rede e clusterização (sub-redes). A ideia de cluster é importante para entender os grupos sociais coesos, isto é, grupo de nós muito conectados, dentro de uma rede maior e que são unidos a outros grupos por algum(ns) de seus membros.

Já o conceito de bub aplica-se a atores altamente conectados, que contribuem significativamente para diminuir a distância entre uma pessoa e outra no sistema, bastando algumas conexões entre os grupos existentes. Sendo assim, poderíamos dizer que a conexão no Twitter se aproxima do modelo "Mundos Pequenos" (WATTS, 2003). Os Mundos Pequenos seriam uma rede na qual as conexões são constituídas pelos vértices mais próximos, sendo que a distância média entre tais vértices teria uma extensão relativamente pequena na rede. Por outro lado, os atores definidos como bubs seriam os "ricos que ficam mais ricos", do modelo "Sem Escala" (BARABÁSI, 2003), ou seja, quanto mais conexões um nó (ator) possui, mais chances ele tem de receber novas conexões. Por essa lógica também um novo nó tende a conectar-se com um nó muito conectado.

No entanto, os modelos de Watts (2003) e Barabási (2003) desconsideram o contexto e o capital social envolvidos nas interações sociais. Por isso, optamos também por aplicar algumas métricas de centralidade, que advém da Análise de Redes Sociais (SCOTT, 2000), a qual tem como objetivo analisar a posição do nó na rede e seus atributos. Ao identificarmos quão central um nó é, estaremos também identificando sua relevância para a rede, como um ator político-social.

\section{RASPAGEM E TABULAÇÃO DE DADOS}

Para a raspagem de dados foi utilizado o software NodeXL ${ }^{6}$. Esse aplicativo, nos fornece algumas informações sobre as postagens, tais como: data, hora, usuário, tipo (tuíte, retuíte, menção), conteúdo, etc. A visualização dos dados ocorre em

6. https://nodexl.com/ 
uma planilha eletrônica. Depois dessa etapa, os dados foram exportados para o programa $\mathrm{Gephi}^{7}$, que "utiliza arestas de forma a gerar gráficos de conexão entre indivíduos de uma mesma rede" (LIMA-LOPES, 2017) e, assim, ser possível analisar os influenciadores, por meio de sua centralidade nos clusters.

Foram calculados os graus médio, ponderados e de visualidade, diâmetro de rede e coeficiente de clustering, obtendo-se, assim: um grafo de toda a rede, figura 1, e mais cinco grafos correspondentes aos clusters (sub-redes), figura 2. Observando o rótulo do nó central (sujeito) de cada sub-rede, voltamos a tabela gerada pelo NodeXL para identificarmos: quantidade de tuítes, retuítes, citações, menções e os próprios tuítes (texto das postagens). Além disso, verificamos no próprio Twitter a descrição do perfil de cada um desses cinco sujeitos, para entendermos seu papel social, sua influência nessas sub-redes, a fim de termos subsídios para análise qualitativa.

Para a análise linguística, utilizamos o banco de dados gerados pelo NodeXL e aplicamos um filtro para mostrar apenas os tuítes, descartando retuítes e menções. Além da necessidade de enxugar o corpus, nos tuítes originais as orações são mais espontâneas do que nos outros dois casos. Depois, foram excluídas as entradas idênticas e as que continham somente a bashtag: \#Dia28EuVouTrabalhar. Por outro lado, a bashtag foi mantida quando era parte da composição da oração, para assegurar o entendimento. Com isso, das 3.437 entradas, chegamos a 185 tuítes. Desse número, apenas dois usaram a basbtag pesquisada para apoio a greve, provavelmente, com intuito de os não apoiadores visualizarem a postagem. Então, descartando também essas duas e as postagens multimodais, que não serão analisadas neste artigo, chegamos a 178 posts para serem classificados de acordo com o Sistema de Avaliatividade.

Notamos que as postagens eram direcionadas a basicamente três grupos: (i) greve ${ }_{i}$ (ii) grevistas e (iii) organizadores. Neste grupo, sob a perspectivas dos internautas, estão: sindicatos, CUT, MST, PT, Lula e esquerda. Cruzamos essas categorias de análise com as subdivisões do Afeto e do Julgamento - Felicidade, Infelicidade, Segurança, Insegurança, Satisfação, Insatisfação, Normalidade, Capacidade, Tenacidade, Propriedade e Veracidade - e montamos uma planilha eletrônica. De acordo com o número de entrada em cada categoria, foi estabelecida a porcentagem para elaboração dos gráficos 1 e 2 .

Os participantes da interação foram denomidados com a letra "S" (de sujeito) seguidos de um número para se manter o anonimato. Também optamos por transcrever os discursos na íntrega, como estavam na base de dados e, por isso, 
alguns não seguem a norma padrão da Língua Portuguesa; ou ainda apresentam características específicas da comunicação em mídias sociais (emoji, representação de risada, entre outras).

\section{RESULTADOS E DISCUSSÕES}

Conforme dito alhures, pelo software Gephi extraímos os cálculos referentes à rede, conforme mostra a tabela 1. Nota-se que as 3.437 postagens (entradas) que esse programa coletou, partiram de 1.951 usuários (nós) e 2.875 conexões (arestas). Isso indica que muitas postagens (aproximadamente 43,24\%) ou eram retuítes ou eram usuários que tuitaram mais de uma vez essa basbtag.

Tabela 1. cálculos da rede

\begin{tabular}{|l|l|}
\hline Entradas & 3437 \\
\hline Nós & 1951 \\
\hline Arestas & 2875 \\
\hline Componentes conectados (exclusivamente entre eles) & 75 \\
\hline Grau médio (Degree) & 2,947 \\
\hline Grau ponderado médio (Weighted Degree) & 1,762 \\
\hline Diâmetro de rede & 07 \\
\hline Densidade do gráfico & 0,603 \\
\hline Coeficiente de clustering médio & 0,061 \\
\hline Número de Comunidades & 146 \\
\hline Peso das arestas & 01 \\
\hline
\end{tabular}

Fonte: base de dados da pesquisa.

Embora essa rede tenha 146 comunidades (tabela 1), aplicando o cálculo da modularidade foram identificados cinco clusters (sub-redes). Com o mesmo aplicativo, foi plotado o grafo a seguir (figura 1) utilizando o algoritmo Force Atlas 2 (RECUERO, 2014), para aproximação dos nós por clusters e seu afastamento de acordo com as conexões. 


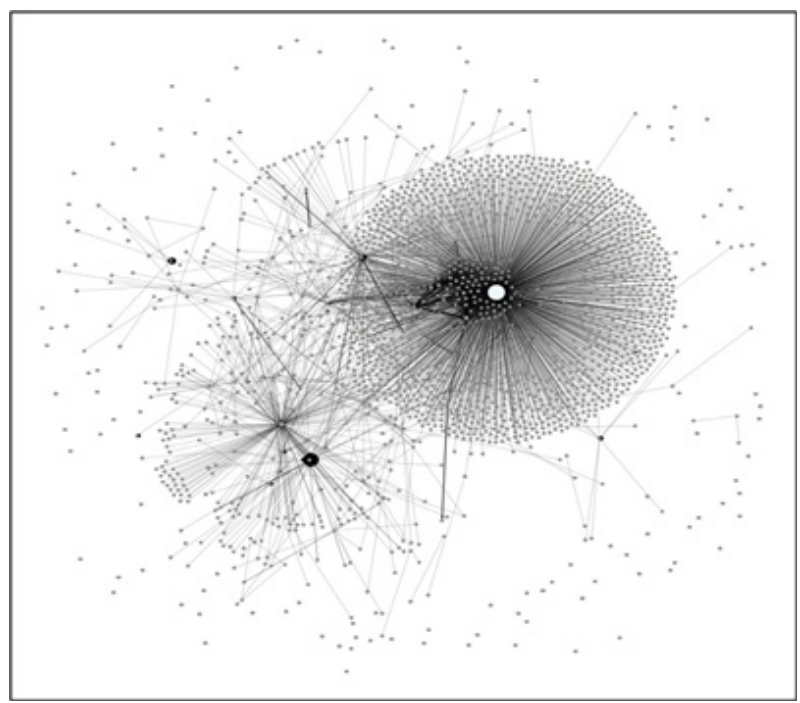

Figura 1. Rede de conexão gerada pela interação em torno da hashtag \#Dia28EuVouTrabalhar Fonte: dados da pesquisa.

Os principais sujeitos da interação (S1, S3, S4 e S5) foram identificados pelas suas centralidades nas sub-redes, conforme demonstra a figura 2. A exceção é referente ao S2 que têm seu grau de importância definido pela interatividade e não por ser central na rede. 

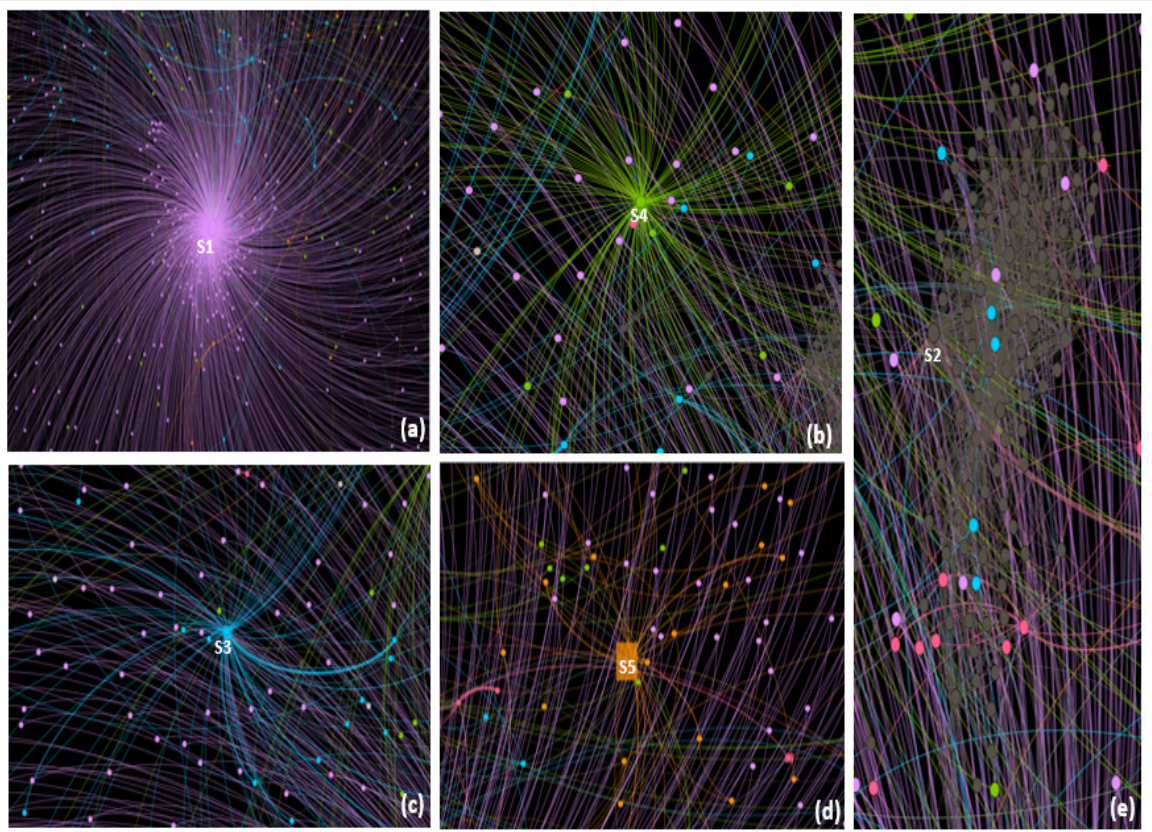

Figura 2. Sub-redes

Fonte: dados da pesquisa.

O S1 marca sua centralidade não somente na sub-rede da figura $2 \mathrm{a}$, mas na rede como um todo (figura 1). Ele possui um grande número de conexões Indegree (número de vezes que foi citado) e também de outdegree (quantidade de retuítes), mostrando sua importância e influência nessa rede. Por isso, atribui-se a ele a centralidade Eingevector. Além disso, é preciso considerar o funcionamento algorítmico do Twitter (BLOMMAERT, 2020). O tuíte produzido por S1 (político, portanto um ator poderoso) é enviado a um algoritmo. Por meio de operações de inteligência artificial o encaminham para vários públicos específicos (nós centrais das sub-redes, figura 2), cujas respostas são retornadas como dados ao algoritmo em sequências ininterruptas de interações indiretas e mediadas. Parte desse público pode retransmitir sua própria aceitação do tuíte (via algoritmo do Twitter) para públicos secundários (os nós periféricos das sub-redes, figura 2), que podem fazer o mesmo, permitindo que um tuíte alcance públicos não acessíveis no início, ou seja, imediatamente após o primeiro ator (S1) tuitar. Embora S1 seja central nessa conversação, ele é um ator não ativo nessa rede, pois não cita e nem responde.

Como no trabalho de Lima-Lopes (2017), procuramos identificar o papel social desses sujeitos para compor a compreensão de sua influência na rede. A 
extração desse dado foi feita da descrição de perfil na conta pessoal do Twitter de cada um (S1 a S5). No caso, a ocupação do S1 pode ter sido fundamental: no momento da coleta era um deputado estadual do Rio de Janeiro de extrema direita, cujo pai, então deputado federal, viria ser candidato a Presidência da República (2018) e, posteriormente, presidente do Brasil (2019-2022). Identifica-se já neste momento, o que Cesarino mais tarde chamou de "primeira camada da bolsoesfera" (CESARINO, 2018, p. 7-8): conteúdo difundido por um político e filho de um candidato. Pela base de dados, gerada pelo programa NodeXL, extraímos algumas postagens de $\mathrm{S} 1$, que foram muito repercutidas:

S1: Você vai trabalhar amanhã, dia 28? Então ajude a compartilhar a hashtag: \#Dia28EuVouTrabalhar

S1: PT gerou 13 milhões de desempregados e agora querem dizer que estão protegendo você trabalhador... \#dia28euvoutrabalhar

A primeira postagem do S1 é o ponto de partida de toda a rede. Nota-se que nela há um apelo pelo compartilhamento da hasbtag. Já a segunda, tenta associar a greve ao PT e, indiretamente, propõe para os que são contra o partido, que compartilhem a basbtag.

Aos sujeitos $\mathrm{S} 2$ a S5 atribuímos a centralidade Betweenness. Eles auxiliaram a espalhar a basbtag e, por isso, funcionaram como ponte entre a rede geral e sua sub-rede correspondente. Há casos em que essa centralidade se deve ao número de citaçãoes que esse sujeito teve. Em outros, deve-se a participação dele na conversa. Vejamos cada um deles.

O S2 é o nó central da sub-rede da figura 2e, identificado pelo tamanho do nó e não por sua posição central no grafo. Na rede analisada, suas postagens foram: 3 tuítes, 5 retuítes, 41 menções e foi citado 118 vezes.

S2: \#Dia28EuVouTrabalhar e eu espero q a polícia trabalhe bastante amanhã e enfie o kct nesses vagabundos

S2: Só vagabundo sustentado a contribuirão sindical ou a corrupção q vai parar amanhã. \#Dia28EuVouTrabalhar

Em seu perfil fica claro seu posicionamento a favor de uma intervenção militar, com esta descrição: "Só a intervenção para limpar o Brasil. Ficou claro ou precisa desenhar?". Em seus tuítes, S2 chama os grevistas de vagabundos e isso pode ter acalorado a discussão, o que talvez explique o grande número de ligações entre os membros dessa sub-rede.

O S3 é o nó central da sub-rede da figura 2c. Ele tuitou 21 vezes e foi citado 125 vezes. Suas principais postagens foram: 
S3: nao vou participar do CARNALULA da CUT, MTST, UNE, PT, PSOL, PSTU nao sou idiota! [os manisfestantes são] Meu partido é o Brasil! \#Dia28EuVouTrabalhar

S3: \#Dia28EuVouTrabalhar Porque greve da CUT, PT e seus puxadinhos os mesmo que ficaram 13 anos no governo ficaram $\$ \$ \$ \$$

Nota-se que o intuito do S3 também é atribuir à greve um caráter político, vindo do PT e seus aliados contra o governo da época. O que contraria o motivo primeiro de toda greve: proteger os trabalhadores e garantir seus direitos.

O S4 é o nó central da sub-rede da Figura 2b com apenas duas postagens. Essa centralidade se deve, muito provavelmente, por ele ter sido citado 172 vezes. Suas duas postagens apenas continham a basbtag pesquisada acompanhada de uma imagem: uma mão segurando a bandeira do Brasil. Na descrição de seu perfil há a frase: "Contra o Comunismo, o Socialismo e o Petismo! (Joaquim Barbosa - fan account)". Como alguns internautas associaram a greve a um movimento do Partido dos Trabalhadores é justificável a sua influência nessa rede.

O S5 é nó central da sub-rede da figura 2d. Suas interações foram: 72 tuítes (com muitas repetições), 22 retuítes e 15 menções. Foi citado 15 vezes. Suas principais postagens:

S5: Fim do imposto sindical obrigatório, na Câmera Federal. Falta passar no Senado. \#Dia28EuVouTrabalhar muito mais feliz!!! $\%$ :-

S5: \#Dia28EuVouTrabalhar. \#GreveNaoApoio. \#GreveNAO. \#CarnaLula. \#PrivatizaTudo. \#AGreveFracassou

Pela descrição de seu perfil não foi possível obter uma pista sobre seu papel social. No entanto, notou-se grande grau de interatividade no Twitter, principalmente reproduzindo muitas postagens (retuítes) por dia. Por esse estilo mais replicador do que formador de opinião, o S5 fez com que sua sub-rede (figura $2 \mathrm{~d}$ ) ficasse menos densa do que as demais. Pelas suas postagens, deixa claro o seu não apoio à greve, pois também a considera como uma manifestação promovida pelo ex-presidente Lula ou, ainda, uma revolta dos sindicatos contra o fim da obrigatoriedade da cobrança da contribuição sindical, proposto na reforma trabalhista.

Em relação ao tipo de rede, pelas conexões entre as sub-redes e entre estas com o nó central (figura 1), nota-se uma aproximação ao modelo de "Mundos Pequenos" (WATTS, 2003), demostrando que as pessoas estão a poucos graus de separação uma das outras. Exemplo: S1-> S2-> nó periférico da sub-rede (e viceversa). Por outro lado, analisando o $\mathrm{S} 1$, central na rede, e associando o número de seguidores dele com o número de conexões obtidas nessa rede, nota-se a lógica dos "ricos ficam mais ricos", do modelo "Sem Escala" (BARABÁSI, 2003), comprovando que quanto mais seguidores, mais chances de conexões com vários grupos. 
Em relação à análise linguística, foram classificadas 178 postagens (exclusivamente texto), considerando apenas as declarações autorais (tuítes). As postagens que continham somente citação à hashtag foram excluídas. Em alguns casos, \#Dia28EuVouTrabalhar fazia parte da estrutura frasal e de seu significado semântico (gramaticalização da basbtag).

Aplicando o Sistema da Avaliativide (MARTIN e WHITE, 2005), iniciamos pela análise do subsistema Afeto. Notamos que a felicidade do emissor manisfetava em relação à greve, devia-se ao fato de estar empregado e, por isso, era contrário à paralisação (S6). A felicidade em relação aos grevistas, girou em torno da ausência destes no trabalho ou, ainda, de uma situação em que os participantes da greve seriam prejudicados (S7 e S8). Em relação aos organizadores só localizamos uma entrada, cuja felicidade era pelo suposto fracasso da greve (S9).

S6: Eu ja estou no trampo e feliz que tenho um emprego.

S7: Que assim seja! Vocês farão falta alguma

S8: Pra quem vai sair para protestar, está caindo uma chuvinha delícia em Goiania [feliz que os grevistas iriam se molhar].

S9: Kkkk Se ferraram sindicatos.

Notem que a linguagem cibernética não tem prosódia, mas conseguimos identificar risada (rsrs), gargalhada (kkkk), entre outras marcações já com sentido negociado entre os participantes da comunicação nesse ambiente digital.

$\mathrm{O}$ sentimento predominante da categoria infelicidade, referindo-se à greve e aos grevistas, era o de raiva, expresso direta ou indiretamente (S10). Já com os organizadores o sentimento de infelicidade era o ódio (S11).

S10: \#Dia28EuVouTrabalhar SÓ DE RAIVA!

S11: Odeio A Esquerda

Os participantes dessa discussão expressaram que sentiriam mais seguros com a proteção da polícia ou do exército. Em relação aos grevistas, queriam que sofressem agressão de policiais (S12). Já em relação à greve, pediram intervenção militar, que seria uma forma de inibir esse tipo de manifestação (S13). O maior sentimento de insegurança em torno da greve geral foi o medo de perder o emprego (S14).

S12: Eu quero ver grevista levando tiro d borracha na cara

S13: Soh os militares podem resolver

S14:\#Dia28EuVouTrabalhar porque senão vem um chinês ocupar o meu lugar 
A satisfação em relação à greve e aos grevistas eram referentes ao suposto fracasso da greve (S15 e S16). Contudo, as manifestações expressas no Twitter em torno dessa hasbtag mostraram, sobretudo, uma insatisfação com o ato de fazer greve (advérbio "não" predominante) e também com os grevistas e com os organizadores (S17 e S18).

S15: Greve Geral furou

S16: Chupa Petralhas [epíteto atribuída aos apoiadores do PT]

S17: Greve Não

S18: Terroristas sim, manifestante não

Ao final, somando as entradas das três colunas (greve, grevistas e organizadores), chegamos ao gráfico do subsistema Afeto (gráfico 1). Nota-se que o sentimento de insatisfação predomina, o que pode estar relacionado a uma repulsa ao PT ou à esquerda e não aos motivos da greve em si.

Gráfico 1. Expressões de afeto

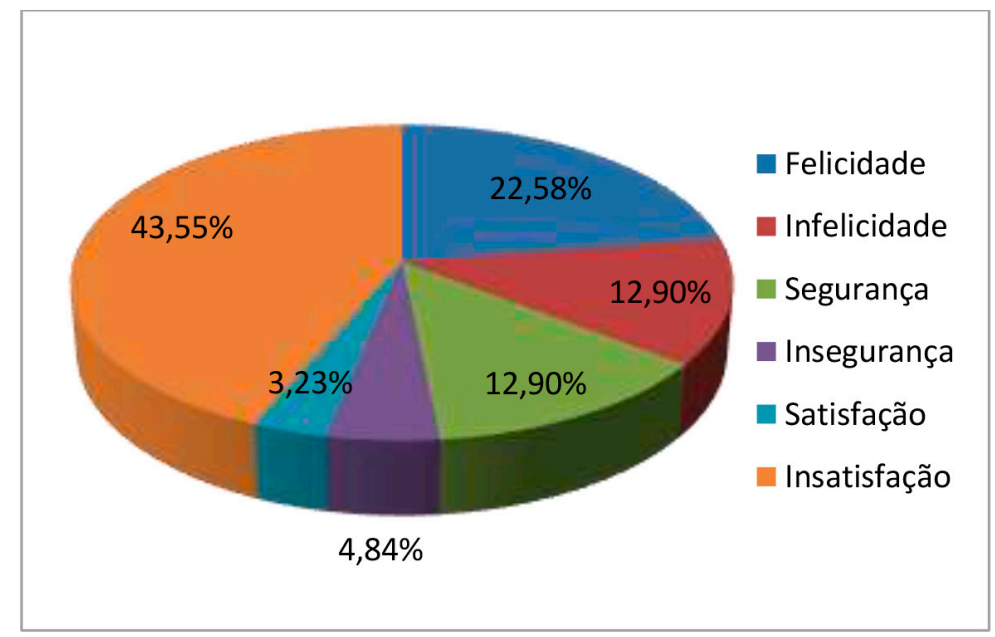

Fonte: dados da pesquisa

Já em relação aos tipos de julgamento, na subdivisão Estima Social, foram inseridas manifestações quanto à Normalidade, Capacidade e Tenacidade, também em relação à greve, aos grevistas e aos organizadores.

A Normalidade diante à convocação de greve geral era de não ir trabalhar. Por outro lado, a bashtag aqui pesquisada foi criada em sentido oposto ao da greve e, por isso, na coleta de dados já eram esperadas muitas manifestações contra a 
paralisação. O destaque fica para as expressões linguísticas que acompanham o ato de ir trabalhar, que também foge de um dia normal de trabalho (S19). Na visão dos indivíduos, que se manifestaram online com essa basbtag, a normalidade esperada pelos organizadores também foi quebrada: em vez de organizarem os trabalhadores e lutarem contra as reformas trabalhistas e de previdência estavam usando a manifestação para fortalecer o PT (S20).

S19: \#Dia28EuVouTrabalhar sem cobrar hora extra

S20: Se você for a esta greve estará apoiando o PT! Cut e principalmente lula! E isso que eles querem te usar

A Capacidade dos três grupos (greve, grevistas e organizadores) foi questionada. Sobre a greve, manifestaram-se incrédulos aos seus objetivos e efeitos (S21); sobre os grevistas, a baixa capacidade intelectual e incapacidade para trabalhar (falta de vontade) (S22) e; sobre os organizadores, além das já mencionadas em relação aos grevistas, queriam observar a capacidade de influência do PT (S23).

S21: Greve de hoje é uma das coisas mais imbecis de todos os tempos!

S22: Vagabundos!

S23: ver se o poder de mobilização do PT voltou ou se sucumbiu de vez!

Adjetivos como vagabundo, vagal ou ainda a expressão "não sou vagabundo" (insinuando que os grevistas eram) foram contabilizados vinte e uma vezes nas postagens analisadas.

Em relação à Tenacidade - o quão resoluta a greve era -, nota-se que desconfiavam de seus reais motivos e, por muitas vezes, foi tachada de movimento pró PT (S24 e S25) e desculpa para emendar o feriado prolongado (S26), que também reforça o estereótipo de vagabundo. Também não mostraram confiança nos organizadores. Alguns sujeitos acharam que eles não irão resolver coisa alguma (S27), pois estariam mais interessados na arrecadação da contribuição sindical do que em lutar pelos direitos dos trabalhadores. Outros internautas diziam, ainda, que a extinção do imposto sindical na pauta da reforma trabalhista seria o real motivo da convocação da greve (S28).

\section{S24: CARNALULA}

S25: greve geral convocada pelo PT, CUT, MST...Vou não!

S26: Greve geral às vésperas do feriadão? rsrsrs

S27: Não vivo às custas de sindicato [os organizadores vivem]

S28: A CUT ta preocupada é com o fim do imposto sindical obrigatório \#Dia28EuVouTrabalhar

Passamos a analisar o julgamento relativo à Sanção Social atribuído às duas categorias de análise: Propriedade (ligada à ética) e Veracidade (se indivíduos ou 
fatos são honestos ou não). Em relação à Propriedade, nas postagens coletadas a visão de seus emissores a greve (S29), os grevistas e os organizadores não são éticos. Notou-se, contudo, que para atacar os grevistas foi usada uma linguagem indireta, destacando uma qualidade do próprio emissor e, com isso, insinuando que os grevistas não agiam da mesma maneira (S30); uma forma de marcar o grupo ao qual pertenciam. Mais uma vez aparece a organização da greve como sendo de responsabilidade do PT, mas dessa vez aliada ao adjetivo corrupto (S31).

S29: Essa greve, pra mim, é uma fachada pro congresso votar em alguma lei, secretamente, a favor deles

S30: Na verdade ja tô trabalhando desde ontem, afinal não ganhei kit mortadela [insinuando que os grevistas ganharam] e nem posso doar sangue pra burlar o sistema [insinuando que os grevistas burlam o sistema].

S31: O PT corrupto com seus sindicatos, não vão me parar!

A segunda parte do Julgamento de Sanção Social refere-se à Veracidade. Nesse quesito, os três grupos avaliados tiveram um retorno negativo dos emissores dos tuítes. A greve foi caracterizada como falsa ou forjada (S32). Os grevistas foram vistos como pessoas desonestas por faltarem ao trabalho para fazer greve (S33). Os organizadores foram tachados de mentirosos (S34).

S32: Pneu queimado não vota! Essa tática é de propaganda da falsa greve! Não seja levado pelas maquinações do PT!

S33: Gente, vamo dormir pq amanhã é dia de luta! [postado no dia 28 após a meia noite] lutar pelo pão de cada dia: coisa de gente honesta e trabalhadora [insinuando que os grevistas não são].

S34: onde tem CUT e MST tem atraso, tem PT, tem mentiras

Para finalizar, foi somado as entradas das três colunas (greve, grevistas e organizadores) e chegamos ao gráfico do subsistema Julgamento (gráfico 2). 
Gráfico 2. Expressões de julgamento

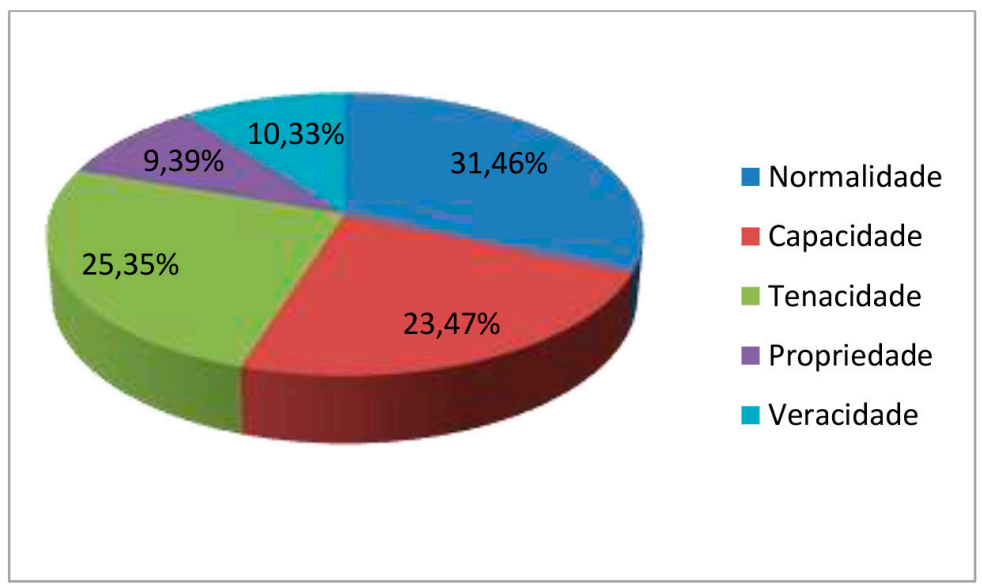

Fonte: dados da pesquisa.

Como já era esperado, quem usou essa bashtag tinha a intenção de não aderir à greve geral e, por isso, muitas expressões reforçavam a normalidade de um dia de trabalho, como algo provocativo, contrariando o proposto: todos os setores deveriam parar. Por isso, a Normalidade aparece numa maior proporção.

O grande número de Julgamentos ligados à Capacidade revela que os sujeitos dessa pesquisa em vez de argumentarem contra a greve ou a favor da reforma trabalhista, proferiram ofensas àqueles que agiram diferentemente do que eles julgam como certo, reforçando o eixo amigo-inimigo. Algumas vezes, colocaram-se ainda em uma posição superior aos grevistas e aos organizadores, autointitulando de mais trabalhador, mais inteligente, mais honesto... Outras vezes desejavam punição física do "outro repugnante" (HARDING, 1991 apud CESARINO, 2020, p. 95) com repreensão policial.

\section{CONCLUSÃO}

Como visto, a análise de rede de conexões teve origem na Matemática, por envolver vários cálculos para se desenhar o grafo. Posteriormente, ela passou a ser utilizada também na análise de Redes Sociais, pelas Ciências Sociais Aplicadas. Na Contemporaneidade essas relações sociais se dão, em grande parte do tempo, em mídias sociais - também chamadas de redes sociais online - tais como Facebook, Twitter, WhatsApp, Instagram, Youtube, etc. Por esse motivo, essas análises de 
conexões aplicadas às redes sociais também migraram para a Internet, como nos mostrou alguns estudos anteriores.

Para este artigo optamos pela junção da Ciência das Redes e a análise discursiva (Avaliatividade), a fim de olharmos o objeto de estudo por duas perspectivas e, consequentemente, enxergar além ou ainda ratificar ou refutar hipóteses. O recorte escolhido para este trabalho procurou evidenciar um tipo de linchamento virtual muito recorrente nas mídias sociais: a intolerância política. Demonstramos por meio da basbtag pesquisada, que ainda há uma forte separação em dois grupos: a esquerda e a direita. Esta análise evidencia estratégias do populismo digital presentes antes mesmo do início da campanha eleitoral (2018), sobretudo a da presidência da República.

Primeiramente, observando o grafo gerado dessas conexões percebemos que o sujeito central (S1) dessa manifestação online tinha intenção de caracterizar a greve como um movimento da esquerda, sobretudo do PT, e que por isso era ruim. O intuito, provavelmente, era conseguir apoiadores para reforçar a sua visibilidade e influência política, já que ele é um político de extrema direita e seu pai, naquele momento, tinha pretensões de entrar na disputa pelo cargo de presidente do país. Ao pesquisar sobre os sujeitos centrais dos demais clusters (S2 a S5) também se notou oposição ao Partido dos Trabalhadores - provável oponente do pai de S1 na disputa presidencial - encontrando, em um dos casos, manifestação favorável à intervenção militar, o que representa inclusive uma oposição à democracia que, desde o impeachment em 2013, vem sendo ameaçada.

Essas evidências foram confirmadas após a análise linguística das 178 postagens (modalidade escrita). O afeto predominante foi a insatisfação, porém não com o motivo da greve, que era contra as reformas trabalhista e da previdência, mas sim com o PT e seus possíveis apoiadores (Lula, grevistas e sindicatos). Quanto ao julgamento, a ética das três categorias de análise foi questionada, muito provavelmente motivados pela divulgação, em mídia híbrida, de esquema de corrupção no período em que o PT esteve na presidência (embora também se tenha noticiado, com menor ênfase, o envolvimento de outros partidos). Além disso, os próprios nós centrais da rede ajudaram com suas postagens a replicar e espalhar a ideia de que a greve era organizada pelo PT - "o partido corrupto que roubou seu dinheiro" - e, por isso, a bashtag contrária à greve deveria ser compartilhada para marcar uma posição ideológica e, assim, deixar claro em que lado estava.

Somado a isso, os adjetivos utilizados para caracterizar os grevistas e organizadores (vagabundos, asnos, burros, manipulados, tralhas, entre outros) comprovam a intolerância em relação ao outro que não segue o padrão do grupo 
formado por essa rede. Os afetos de infelicidade expressos (ódio e raiva) corroboram com esse desejo de padronização de sujeitos e seus ideais.

Atualmente, após quase três anos da aprovação da reforma trabalhista, os trabalhadores estão vivenciando as mudanças e experienciando seus efeitos. Além disso, em estudos posteriores (CESARINO, 2018, 2020) é possível comprovar que as táticas presentes nesta pesquisa de 2017, continuaram e foram tomando corpo no populismo contemporâneo atuando em mídias sociais, tais como: um ator que mobiliza um discurso "a favor" do povo; aceitação e reconhecimento de um grupo (seguidores, militantes) que compartilham esse discurso $e_{;}$a construção de si (como ser superior), baseada na desmoralização do "outro" seja ele político da oposição, seja pessoa comum que o apoia. Então, esperamos que este artigo desperte novas reflexões ao se comparar passado e presente.

Agradecimentos

O presente trabalho foi realizado com apoio da Coordenação de Aperfeiçoamento de Pessoal de Nível Superior - Brasil (CAPES) - Código de Financiamento 001. Rodrigo Esteves de Lima-Lopes agrade ao CNPq (processo 422111/2018-0) pelo financiamento.

\section{REFERÊNCIAS}

ALMEIDA, F. S. D. P. (2010) Atitude: afeto, julgamento e apreciação. In: Vian Jr, O.; De Souza, A. A.; Almeida, F. S. D. P. (org). A linguagem da Avaliação em Língua Portuguesa: estudos sistêmicos-funcionais no sistema da Avaliatividade. São Carlos: Pedro \& João Editores, pp. 99-112.

BARABÁSI, A-L. (2003). Linked. How Everything is Connected to Everything else and What it means for Business, Science and Everydai Life. Cambridge: Plume.

BARABÁSI, A.-L.; ALBERT, R. (1999) Emergence of Scaling in Random Networks. Science, v. 286, n. October, p. 509-512.

BLOMMAERT, J. (2020) Political discourse in post-digital societies. Trabalhos em Linguística Aplicada, v. 59, n. 1, p. 390-403.

BONACICH, P. (1972) Factoring and weighting approaches to status scores and clique identification. Journal of Mathematical Sociology. v. 2, pp. 113-120 
CABRAL, S. R. S. (2007). A mídia e o presidente: um julgamento com base na teoria da valoração. Tese de Doutorado em Letras. Universidade Federal de Santa Maria, Santa Maria-RS.

CASTELLS, M. (2014). Redes de indignação e esperança Movimentos sociais na era da internet. Rio de Janeiro: Zahar.

CASTELLS, M.; QUI J. L.; FERNANDEZ-ARDEVOL, M.; SEY, A. (2006) Mobile Communication and Society: A Global Perspective. Boston: MIT Press.

CESARINO, L. (2018) Populismo digital: roteiro inicial para um conceito, a partir de um estudo de caso da campanba eleitoral de 2018. Disponível em: < https://www.academia.edu/38061666/ Populismo_digital_roteiro_inicial_para_um_conceito_a_partir_de_um_estudo_ de_caso_da_campanha_eleitoral_de_2018>. Acesso em: 17 jun, 2020.

CESARINO, L. (2020) Como vencer uma eleição sem sair de casa: a ascensão do populismo digital no Brasil. Internet \& Sociedade, v. 1, n. 1, p. 91-120.

FREEMAN, L. (1979). Centrality in social networks: Conceptual clarification. Social Networks, v.1, pp. 215-239.

HALLIDAY, M. A. K.; MATTHIESSEN, C. M. I. M. (2014) Halliday's introduction to functional grammar. Fourth Edition, Oxon: Routledge.

HARDING, S. (1991). Representing fundamentalism: the problem of the repugnant cultural other. Social Research,v. 58, n. 2, p. 373-393.

HOFFMAN, D. S. (1996) The Web of Hate: Extremists Exploit the Internet. Washington: AntiDefamation League.

LIMA-LOPES, R. E. (2017) Análise de registro e ciência das redes estudando um grupo de WhatsApp dedicado à produção de cerveja artesanal. Revista Hipertextus, v.16, pp. 134-161.

LIMA-LOPES, R. E. (2018) O conservadorismo como ideologia: contribuições da ciência das redes para a Linguística Sistêmico-Funcional. Revista Letras, n. 56, p. 42-70.

MACEDO, K. T. M. (2018). Conflitos Sociais Contemporâneos: possíveis causas e consequências dos Linchamentos Virtuais. Humanidades \& Inovação, v. 5, n. 4, p. 197-208.

MALY, I. (2020). Algorithmic populism and the datafication and gamification of the people by Flemish Interest in Belgium. Trabalhos em Linguística Aplicada, v. 59, n. 1, p. 444-468. 
MARTIN, J. R.; WHITE, P. R. (2005) The Language of Evaluation. Basingstoke: Palgrave Macmillan, v. 2.

MERCURI, K. T. (2016) Linchamentos Virtuais: paradoxos nas relações sociais contemporâneas. Dissertação de Mestrado Interdisciplinar em Ciências Humanas e Sociais Aplicadas. Faculdade de Ciências Aplicadas, UNICAMP, Limeira-SP.

NATIONAL ACADEMY OF SCIENCES (ED.) (2005). Network science. Washington: National Academies Press.

RECUERO, R. C. (2005) Redes Sociais na Internet: considerações iniciais. E Compós, v. 2, pp. $1-17$.

RECUERO, R. C. (2014) Métricas de Centralidade e Conversações em Redes Sociais na Internet: Desvelando Estratégias nos Debates Presidenciais de 2014. In: VIII Simpósio Nacional da ABCiber: Comunicação e Cultura na Era de Tecnologias Midiáticas Onipresentes e Oniscientes. São Paulo: ESPM, pp. 1-18.

SAFATLE, V. P. Por um colapso do indivíduo e de seus afetos. Disponível em: < https:// www.youtube.com/watch?v= enBrMfYeZIs >. Acesso em: 28 jun, 2016.

SCOTT, J. (2000). Social Network Analysis: A bandbook. New York: SAGE Publications.

SCOTT, J. (2013). What is social network analysis? London; New York: Bloomsbury Academic.

THOMPSON, G.; ALBA-JUEZ, L. (2014). Evaluation in context. Philadelphia: John Benjamins Publishing Company.

VIAN JR, O.; De Souza, A. A.; ALMEIDA, F. S. D. P. (2010). A linguagem da Avaliação em Lingua Portuguesa: estudos sistêmicos-funcionais no sistema da Avaliatividade. São Carlos: Pedro \& João Editores.

WATTS, D. J. (2003) Six Degrees. The Science of a Connected Age. New York: W. W. Norton \&Company.

Recebido: 20/2/2020

Aceito: 16/6/2020

Publicado: 24/7/2020 